Funfak, Anette; Cao, Jialan; Knauer, Andrea; Martin, Karin; Köhler, J. Michael:

Synergistic effects of metal nanoparticles and a phenolic uncoupler using microdroplet-based two-dimensional approach

URN: $\quad$ urn:nbn:de:gbv:ilm1-2014210137

Published OpenAccess: September 2014

Original published in:

Journal of environmental monitoring : JEM. - London : Royal Society of

Chemistry (ISSN 1464-0333). - 2 (2011) 13, S. 410-415.

DOI: $\quad 10.1039 /$ COEM00162G

URL: $\quad$ http://dx.doi.org/10.1039/COEM00162G

[Visited: 2014-09-09]

„Im Rahmen der hochschulweiten Open-Access-Strategie für die Zweitveröffentlichung identifiziert durch die Universitätsbibliothek Ilmenau."

"Within the academic Open Access Strategy identified for deposition by Ilmenau University Library."

"Dieser Beitrag ist mit Zustimmung des Rechteinhabers aufgrund einer (DFG-geförderten) Allianz- bzw. Nationallizenz frei zugänglich."

"This publication is with permission of the rights owner freely accessible due to an Alliance licence and a national licence (funded by the DFG, German Research Foundation) respectively."

\section{DFG}

Nationallizenzen 


\title{
Synergistic effects of metal nanoparticles and a phenolic uncoupler using microdroplet-based two-dimensional approach
}

\author{
Anette Funfak, ${ }^{* a}$ Jialan Cao, ${ }^{a}$ Andrea Knauer, ${ }^{a}$ Karin Martin ${ }^{b}$ and J. Michael Köhler ${ }^{a}$ \\ Received 27th April 2010, Accepted 11th November 2010 \\ DOI: $10.1039 / \mathrm{c} 0 \mathrm{em} 00162 \mathrm{~g}$
}

\begin{abstract}
A droplet-based microfluidic technique for testing multiple reagent concentrations is presented. We used this experimental approach to study combined effects of gold (AuNP) and silver nanoparticles (AgNP) with the phenolic uncoupler 2,4-dinitrophenol (DNP) with respect to the growth of Escherichia coli. In order to evaluate the toxicity of binary mixtures, we first encapsulated the $E$. coli cells and particle mixtures inside the microdroplets using PEEK (polyetherketone) modules. Two-dimensional concentration spaces with about 500 well separated droplets were addressed. We subsequently analyzed the cell growth, the viability and the autofluorescence intensity (metabolic activity) of the bacteria with a micro-flow-through fluorometer and photometer. Dose-dependent synergistic effects were found for the binary mixture of AgNPs and DNP, which indicated a stronger interaction in the mixture than it was expected from effect summation. For the binary mixture of DNP and AuNPs in non-toxic concentrations, we found only weak synergistic effects at low DNP concentrations. Furthermore, the non-toxic tested AuNPs causes effect summation in the binary mixture with the phenolic uncoupler. In general, we demonstrated the efficiency of a droplet-based microfluidic system for fast high-throughput screenings of binary and multiple mixtures. This work also confirmed the relevance of highly resolved droplet-based assays for the miniaturization of ecotoxicological aquatic test systems.
\end{abstract}

\section{Introduction}

Metal nanoparticles have attracted increasing scientific as well as technical interest because of their unique set of physical and chemical properties. Due to their spectral features as well as their electronic and catalytic behaviour, they are part of a material class with several promising applications. ${ }^{1-4}$ A key feature of nanoparticles is that their properties can be tuned by the judicious choice of the core material and are strongly influenced by their size, shape and surface state. ${ }^{5}$

The toxicological implications of metal nanoparticles are comparatively simple to understand if the particles are completely corroded and the resulting metal ions are released into the solution. The effect of the corrosion products is mainly given by the concentration of free ions, the solubility of salts formed by the ions and their coordination chemistry. ${ }^{6}$ The situ-

${ }^{a}$ Department of Physical Chemistry/Microreaction Technology, Institute of Physics, Ilmenau University of Technology, Weimarer Str. 32, 98693 Ilmenau, Germany. E-mail: anette@ladhyx.polytechnique.fr

${ }^{b}$ Hans Knöll Institute for Natural Products Research, Beutenberg Str. 11, 07745 Jena, Germany ation becomes much more complicated if the nanoparticles are more or less stable. In this case, the interaction of the material with tissues, cells and membranes is additionally controlled by shape and size as well as their mobility, interaction potential, aggregation behaviour, their electrical charges and chemical surface state. In particular, the last two mentioned parameters are strongly affected by the chemical environment. Since nanoparticles possess a very high specific surface area, any chemical species of a liquid matrix can interact with this surface by unspecific adsorption, specific binding and other chemical reactions. Therefore, it is reasonable to expect that the effects of nanoparticles on cells are strongly dependent on the chemical composition of the matrix. ${ }^{7,8}$

The high chemical activity of nanoparticles can be explained by the presence of a large number of surface binding sites with high local energy. In particular, small spherical particles show unexpected chemical properties due to active sites on crystal edges and corners resulting from the presence of small-sized crystal planes of high indices. The constitutional properties of a certain type of nanoparticle lead to a specific chemical behavior. As a result, less reactive or even inert materials as some noble metals are converted into highly reactive materials with

\section{Environmental impact}

There are a huge number of consumer products which contain nanomaterials, nowadays. The environmental impact of the released nanoparticles is not yet predictable. Even less is known about the effect of nanoparticles in chemical mixtures, which describe the real status in our environment. In this work we report the application of a droplet-based microfluidic set-up opens an efficient way for evaluating mixture effects of pollutants and interferences of nanoparticles with other substances. The study shows the effects of silver and gold nanoparticles in binary mixture with a phenolic uncoupler on the bacteria Escherichia coli. We believe that the potential of droplet-based microfluidic allows future high resolved ecotoxicologic screenings of mixtures toxicity within the nanolitre range. 
surprising effects if these materials are nanosized. This is not only the case for platinum, palladium and silver with their well-known catalytic activities, but also for gold. ${ }^{9,10}$ For example, it was found that gold nanoparticles can catalyze organic reactions as partial oxidation of olefins with high specificity. ${ }^{11}$

The evaluation of the toxic potential of nanoparticles must reconsider the specificity of nanoparticles and their chemical state. Therefore, the determination of MIC (minimum inhibitory concentration) or EC50 (effective concentration 50\%) values must be strongly related to the matrix conditions. ${ }^{12}$ Besides, contaminated systems will probably be polluted with mixtures of pollutants, leading to possible interactions and changes in their effectiveness. This results in a combinatorial problem and demands combinatorial screenings for the toxicological properties of nanoparticles. In this case, the well-introduced classical toxicological information from a minimum of cells and chemicals are required.

The microdroplet-based flow offers some important advantages over techniques based on micro- and nanotiterplates or conventional ecotoxicological methods for solving the problem of screening a complex parameter field. Besides the high throughput of small volumes, the significantly reduced evaporation, the reduced wall contact and the mixing by segmentinternal convection make the microdroplet-based flow ideal for screening operation. Thereby, an aqueous cultivation phase is subdivided into a lot of small and well separated aliquots by injection into a water-immiscible inert liquid. ${ }^{13,14}$

Microdroplets are generated readily by microfluidic actuation. In this manner, microdroplet sequences with hundreds or thousands of well-defined aliquots can be generated in only a few seconds or minutes. The volumes and the concentrations of the separated liquids can be set with astonishing precision up to picolitre and picomolar range. ${ }^{15}$

It was shown that this technique can be applied for analytical purposes, chemical synthesis, cell cultivation and screenings with microorganisms as well as multicellular systems. ${ }^{\mathbf{8 1 6 - 2 0}}$ Information about cell density or physiological activities inside the fluid droplets can be extracted non-invasively by microphotometric or microfluorimetric methods. Thus, this method is well suited for quantitative measurements with small sample volumes and for highly parallelized screenings. In this paper, the droplet-based flow principle is introduced for studying synergistic effects of colloidal suspensions of gold and silver nanoparticles with 2,4DNP which is known to be an important pollutant.

\section{Materials and methods}

\section{Chemicals}

The following chemicals were used: 2,4-dinitrophenol (DNP, Acros), perfluoromethyldecalin (PP9, F2 Chemicals Ltd), cochineal red A (VWR), indigo carmine (Fluka Analytical), silver nitrate $\left(\mathrm{AgNO}_{3}\right.$, Merck-Schuchardt), 25\% ammonia solution (Merck-Schuchardt), D-(+)-glucose (dextrose, Carl Roth), nitric acid $\left(\mathrm{HNO}_{3}\right.$, Merck-Schuchardt), sodium hydroxide ( $\mathrm{NaOH}$, Merck-Schuchardt), hydrogen tetrachloroaurate trihydrate $\left(\mathrm{HAuCl}_{4}, \mathrm{Carl}\right.$ Roth), L-(+)-ascorbic acid $\left(\mathrm{C}_{6} \mathrm{H}_{8} \mathrm{O}_{6}\right.$, Merck) and ammonium chloride $\left(\mathrm{NH}_{4} \mathrm{Cl}\right.$, Merck). The synthetic medium was composed of the following components: $0.56 \mathrm{~g} \mathrm{~K}_{2} \mathrm{HPO}_{4}, 0.3$ $\mathrm{g} \mathrm{KH}_{2} \mathrm{PO}_{4}, 0.012 \mathrm{~g} \mathrm{MgSO}_{4} \times 7 \mathrm{H}_{2} \mathrm{O}, 0.1 \mathrm{~g} \mathrm{NH}_{4} \mathrm{Cl}$ in $90 \mathrm{~mL}$

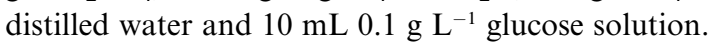

\section{Biological material and preparation of samples}

The experiments were performed with the Gram-negative bacteria Escherichia coli (strain RV308 provided by the HansKnöll institute (HKI), Jena, Germany). The bacterial preculturing was carried out in synthetic medium under stirring for $24 \mathrm{~h}$ at $37^{\circ} \mathrm{C}$.

The inoculum cell density was adjusted to 100000 cells $\mathrm{mL}^{-1}$ by the adequate dilution in synthetic medium. The cell cultures had been attached in the lag-phase and the early exponential phase of bacterial growth. The indicator dyes cochineal red A $(0.004 \%)$ and indigo carmine $(0.01 \%)$ were added to the cell suspension. The initial concentration of the effector suspensions for AuNP, AgNP and 2,4-DNP was adjusted to $20 \mathrm{pmoL}$ (particle) $\mathrm{L}^{-1}, 0.3 \mathrm{pmoL}$ (particle) $\mathrm{L}^{-1}$ and $300 \mu \mathrm{moL} \mathrm{L}{ }^{-1}$.

For the detection of the concentration distribution inside the droplets cochineal red $\mathrm{A}$ and indigo carmine had been added as indicator dyes to the effectors. The distribution of the effectors in the droplets is expected to be same as the indicator dyes. To distinguish between the concentration setting of the different effectors within the droplets two different indicator dyes had been used.

For the monitoring of the concentration setting inside the nanolitre droplets, the indicator dye cochineal red A $(0.004 \%)$ was added to the AuNP and AgNP suspension as well as the indicator dye indigo carmine $(0.01 \%)$ to the DNP-solution.

\section{Preparation of silver and gold nanoparticles}

The synthesis of silver nanoparticles was performed according to the specification listed in Kvitek et al. ${ }^{21}$ using D-(+)-glucose for the reduction of the complex anion $\left[\mathrm{Ag}\left(\mathrm{NH}_{3}\right)_{2}\right]^{+}$in alkali media [pH 12.5] at $23{ }^{\circ} \mathrm{C}$. The synthesis of gold nanoparticles was carried out by the reduction of tetrachloroaurate with ascorbic acid at $23{ }^{\circ} \mathrm{C}$. In this case, $2 \mathrm{~mL}$ of $1 \mathrm{mmoL} \mathrm{L}^{-1}$ of $\mathrm{HAuCL}_{4}$ and $0.1 \mathrm{~mL}$ of $0.1 \mathrm{moL} \mathrm{L}^{-1}$ ascorbic acid had been mixed and diluted with $5 \mathrm{~mL}$ distilled water.

The number and weight related size distribution of the synthesized metal nanoparticles was characterized by differential centrifugal sedimentation (DCS, using DC 20000, CPS Instruments Inc., USA (see Table 1)). The dimensions and shapes of the gold and silver nanoparticles were determined by scanning electron microscopy (SEM, JSM 6700, JEOL USA) and transmission electron microscopy (TEM, Philips Tecnai 20 S-TWIN)

Table 1 Average particle size and initial concentration of the prepared metal nanoparticles

\begin{tabular}{|c|c|c|c|}
\hline $\begin{array}{l}\text { Metal } \\
\text { nanoparticles }\end{array}$ & $\begin{array}{l}\text { Particle size }{ }^{a} \\
\text { half-width/nm }\end{array}$ & $\begin{array}{l}\text { Particle size }{ }^{a} \\
\text { half-width/nm }\end{array}$ & $\begin{array}{l}\text { Initial concentration } \\
\text { of metal nanoparticles } \\
\text { (related to particle } \\
\text { type A)/pmoL L L }\end{array}$ \\
\hline AuNP & $30 / 11.5$ & $3 / 0.3$ & 10 \\
\hline $\mathrm{AgNP}$ & $21.2 / 9$ & $2.8 / 1.9$ & 0.15 \\
\hline
\end{tabular}



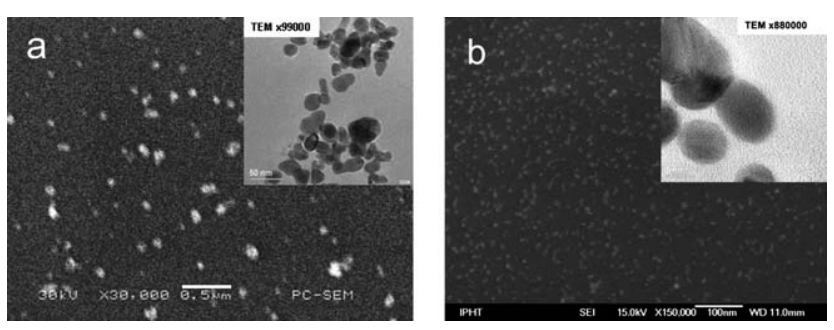

Fig. 1 SEM and TEM images of silver (a) and gold nanoparticles (b).

(Fig. 1). The influence of the synthetic cultivation medium on gold as well as the silver nanoparticles was investigated by UV/ VIS spectroscopy (Specord 2000, Analytik Jena AG, Germany). The composition of the reagents in the UV-cuvette had been set identical to the microdroplets composition. After mixing the colloidal suspension and the cultivation buffer without cells the optical spectra of the colloidal suspensions were registered immediately within $24 \mathrm{~h}$ and $48 \mathrm{~h}$ after incubation at $37{ }^{\circ} \mathrm{C}$. Control experiments with pure water were executed in parallel.

The influence of nanoparticles on the light scattering was corrected by setting the measurement signals against the reference signal $(t=0 \mathrm{~h})$. The ion strength during the nanoparticle synthesis was given by the concentration of dissociation products of the applied reactants. The size of nanoparticles is effected by the ratio of nucleation and particle growth. It can be controlled by the reactant concentration.

\section{Instrumentation}

A microfluidic system was used for the monitoring of single and two-dimensional dose-response relationships (Fig. 2). The generation of the microdroplet sequences was realized in a 7Port-Peek Manifold (Upchurch, Washington) by targeted dosing of bacteria suspension and chemical substances into a carrier liquid (perfluoromethyldecalin, PP9). Therefore, the manifold was connected through Teflon ${ }^{\circledR}$ tubes $(0.5 \mathrm{~mm}$ ID, Bohlender
GmbH, Grünsfeld, Germany) with a computer-controlled syringe pump equipped with six dosing units (Cetoni $\mathrm{GmbH}$, Korbußen, Germany), and syringes (ILS, Stützerbach, Germany) with volumes of $500 \mu \mathrm{L}$ and $2500 \mu \mathrm{L}$ for the samples and the carrier liquid, respectively. For homogeneous loading of the cells inside the microdroplets, an integrated syringe stirring system (neMIX, Cetoni GmbH) was used at $650 \mathrm{rpm}$ (Fig. 2a).

The fluid flow was controlled using a software based on LabVIEWTM (National Instruments) for the single and twodimensional concentration adjustment inside the microdroplets. The binary mixtures were performed in a $\left(n^{2}+n\right) / 2$ design inside the 7-Port Manifold by a flow rate controlled variation of substance A, substance B and cultivation medium whereas the flow rate of the cell suspension was kept constant. For each concentration, six to seven microdroplets were generated, whereas for the positive control (only cells) the first 10 microdroplets were addressed. Each sequence comprised 400 to 500 microdroplets with a volume of about $600 \mathrm{~nL}$. The flow rates of the carrier liquid and samples were regulated at $40 \mu \mathrm{L} \mathrm{min}{ }^{-1}$ and $4 \mu \mathrm{L} \min ^{-1}$ and the total flow rate for the generation process was

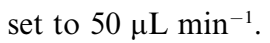

The experimental data were set according to the concentration addition model irrespective of the underlying modes of action and illustrate in isobolograms. The EC(50) values from the doseresponse curves of the single substances were obtained by appropriate fits of the data points. The term "synergism" was used to describe stronger effects of the mixtures as expected from concentration addition.

The monitoring of the microdroplet signal was performed directly inside a transparent FEP-tubing (Upchurch). The combined application of a micro-flow-through photometer and fluorometer allowed the simultaneous measurement of the scattered light and fluorescence intensity (Fig. 2b). Two light emitting diodes (LED, Agilent, Santa Clara CA, United States) with a peak wavelength of $505 \mathrm{~nm}$ and $610 \mathrm{~nm}$ were used for the scattering measurement and absorbance detection of the indicator dyes.

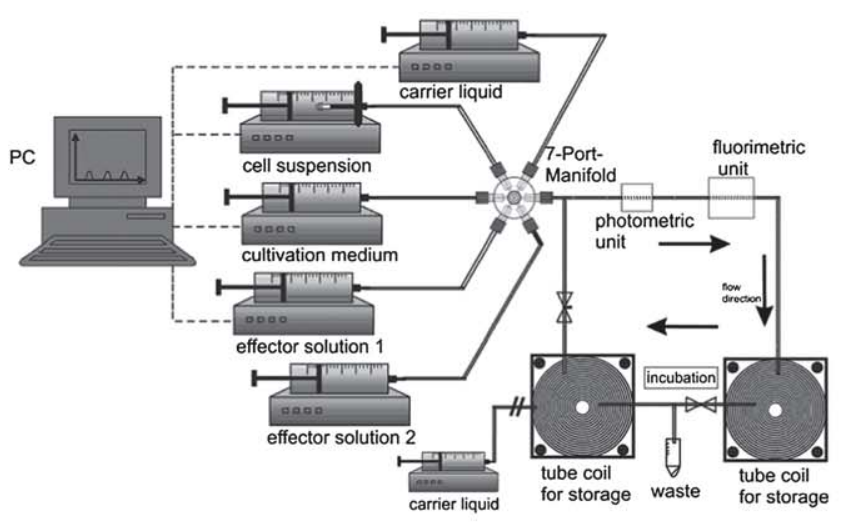

a

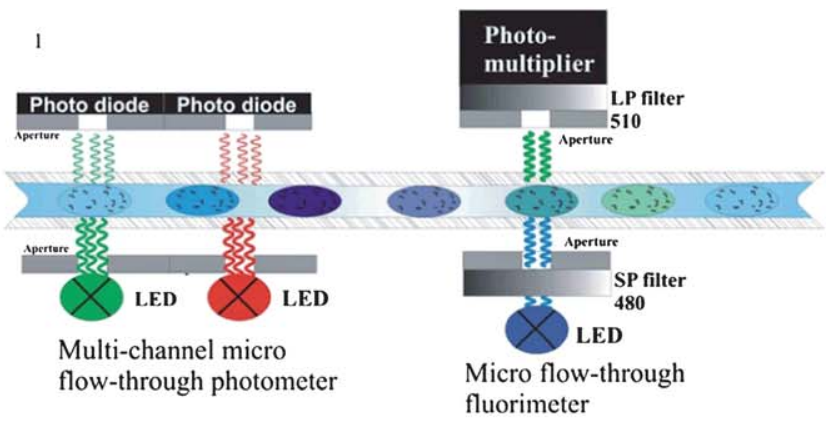

2

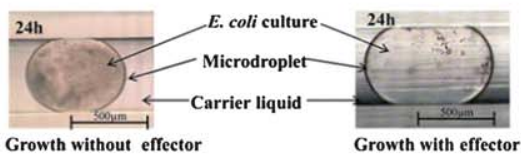

b

Fig. 2 Experimental set-up for the generation and the analysis of microdroplets for one- and two-dimensional toxicological screenings. (a) Scheme of the experimental set-up. (b) 1. Pathway for detection of microdroplet sequences. 2. Growth of E. coli in microdroplets with and without the presence of a binary mixture. 
For detecting the autofluorescence signal of $E$. coli the excitation (LED, $470 \mathrm{~nm}$, CML, Bayern, Germany)/emission wavelength of the micro-flow-through fluorometer were set to $480 \mathrm{~nm} /$ $510 \mathrm{~nm}$ through appropriate filters (Laser Components $\mathrm{GmbH}$, Olching, Germany). An aperture with a split width of $1 \mathrm{~mm}$ focused the light beam onto the tube.

A tube coil was used to store the generated segment sequences between every measurement.

\section{Results and discussion}

\section{Interaction between cultivation buffer (synthetic medium) and nanoparticles in the absence of cells}

The stability of the colloidal systems depends on the electrical surface state of the particles, which is influenced by ligands, $\mathrm{pH}$ and ionic strength of the suspension..$^{22}$ Therefore, the effect of the cultivation medium on the nanoparticle suspensions was checked in the absence of cells. Changes in the colloidal suspension are indicated by a response of the optical absorption to the changes of the surrounding medium.

All samples showed a change of the optical spectra over time. The silver plasmon absorption at $410 \mathrm{~nm}$ shows a strong decrease in absorbance and a hypsochromic shift after one and two days incubation if the colloidal suspension was mixed in the cultivation medium. And a new, small absorption band appeared at about $350 \mathrm{~nm}$. On the other hand, the plasmon absorption band of gold nanoparticles is immediately affected by the cultivation medium. The shape of optical spectra changed instantaneously after mixing. The behavior of the nanoparticles can be interpreted by an aggregation and sedimentation of nanoparticles and adsorption at the surface of the cuvette wall. In the case of silver the strong reduction of original absorption and the arising shortwave length band could also be due to an oxidation of silver nanoparticles.

In conclusion, it can be expected that the effective concentrations of metal nanoparticles and the size of the nanoparticles are lower/bigger in the microtoxicological screenings as estimated from the suspension ratio in the preparation. So, the given nanoparticle concentrations are upper limits for the presence of metal nanoparticles.

\section{Microtoxicological screening of the binary mixture of gold nanoparticles and DNP inside microdroplets}

Gold nanoparticles are regarded to be non-toxic in the past because bulky gold was found to be bio-inert. ${ }^{23}$ However, some pharmaceutical studies indicate a physiological activity of gold nanoparticles. ${ }^{24}$ This motivates detailed investigations on the toxicity of noble metal nanoparticles such as gold and in particular those in the presence of other toxic substances.

The toxic effect of gold nanoparticles was checked in the presence of 2,4-dinitrophenol (DNP) as an example of a wellknown cell-damaging aromatic compound. In this case, the complete two-dimensional concentration space between 0 and 10 $\mathrm{pM}$ gold nanoparticles and 0 and $150 \mu \mathrm{moL} \mathrm{L^{-1 }}$ DNP was covered by a droplet-sequence containing approximately 500 single and well-separated microdroplets. Additionally, onedimensional screenings of AuNPs and DNP were carried out in microdroplets (Fig. 3). The growth of bacteria was monitored by
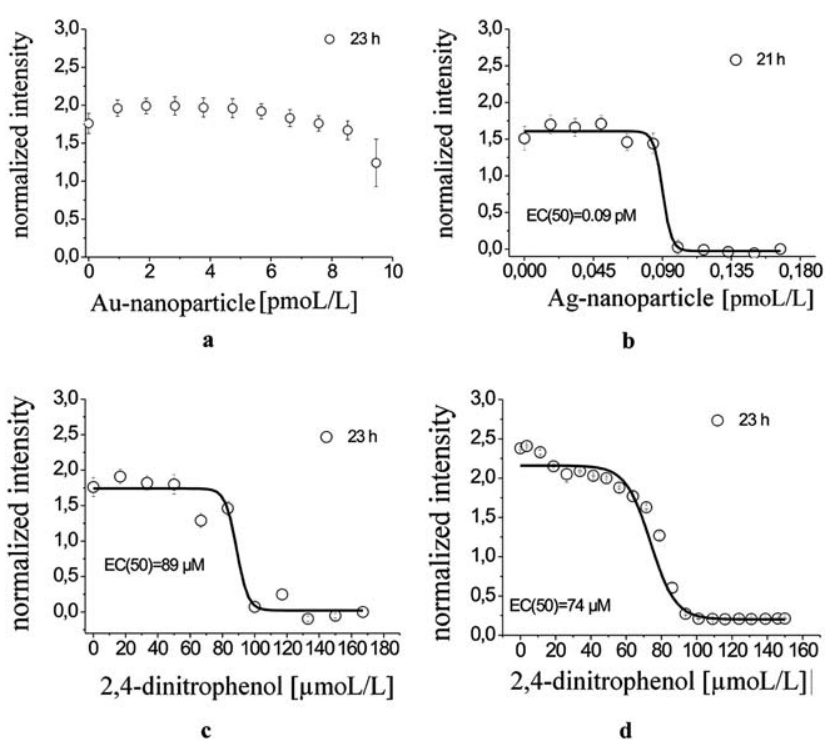

Fig. 3 Dose-response curves for the single effectors DNP and AuNPs and their binary mixture on the autofluorescence intensity of $E$. coli after $24 \mathrm{~h}$ cultivation in microdroplets. The normalized intensity $\dagger$ was determined from nearly 500 microdroplets for two-dimensional and 200 for one-dimensional screening respectively. (a) Single effect of AuNPs determined by two-dimensional screening at a DNP concentration of $0 \mu \mathrm{moL} \mathrm{L}^{-1}$. (b) Single effect of AgNPs determined by two-dimensional screening at a DNP concentration of $0 \mu \mathrm{moL} \mathrm{L}^{-1}$. (c) Single effect of DNP determined by two-dimensional screening at a AuNP concentration of $0 \mathrm{pM}$. (d) Single effect of DNP determined by one-dimensional screening.

measuring the increase of cell density by light scattering and the metabolic activity by microfluorimetric measurements of the endogenous cellular autofluorescence.

The effect-screening of the gold nanoparticle suspension ( 30 $\mathrm{nm}$ diameter) in microdroplets showed non-toxic effects on the autofluorescence signals of the E. coli bacteria for particle concentrations up to $10 \mathrm{pM}$ (Fig. 3a). In ref. 10 the effects of functionalized $2 \mathrm{~nm}$ gold nanoparticles on an $E$. coli species had been specified with $\mathrm{LC}(50)$ values of $3 \mu \mathrm{moL} \mathrm{L}{ }^{-1}$ for cationic and $>28 \mu \mathrm{moL} \mathrm{L}{ }^{-1}$ for anionic side chains of the functionalizing groups. In ref. 25 non-toxic effects were found for unmodified 10 $\mathrm{nm}$ gold nanoparticles up to concentrations of $1 \mathrm{mg} \mathrm{L}^{-1}$.

The EC(50) value, defined as the concentration which causes $50 \%$ reduction in autofluorescence signal of E. coli compared with the controls, for the phenolic uncoupler DNP was deter-

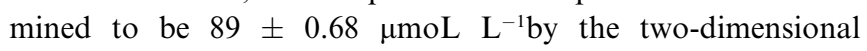
screening (Fig. 3c) and $74 \pm 0.7 \mu \mathrm{moL} \mathrm{L}{ }^{-1}$ by the one-dimensional screening (Fig. 3d) in microdroplets. Nearly the same effective concentration levels were thus found for both screening procedures.

In Fig. 4 the weak interactions of the binary mixture are shown for the growth, measured as optical density (Fig. 4a), and the autofluorescence (Fig. 4b) of the bacteria culture. Both diagrams show similar response of the cell culture as a function of the different concentration pairs of the effectors. The two-dimensional screening experiments allowed the simultaneous

$\dagger$ Normalized intensity $=$ intensity signal/base signal. 

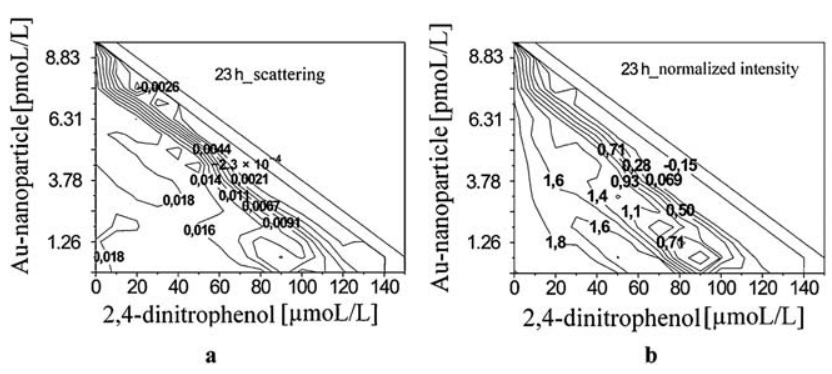

Fig. 4 Isoboles showing weak interactions up to zero interactions between the phenolic uncoupler DNP and gold nanoparticles. (a) Effects of the binary mixture on the growth (optical density) of $E$. coli after $24 \mathrm{~h}$ cultivation inside microdroplets. (b) Effects of the binary mixture on the autofluorescence of $E$. coli after 24 h cultivation inside microdroplets.

determination of a complete set of EC50 values for DNP within the whole range of investigated gold nanoparticle concentrations. The application of gold nanoparticles caused a reduction of critical concentration of DNP. Whereas the lethal concentration of DNP was about $100 \mathrm{pM}$ in the absence of nanoparticles it is lowered to about $80 \mathrm{pM}$ at a nanoparticle concentration of $3 \mathrm{pM}$ and to $40 \mathrm{pM}$ at a nanoparticle concentration of about $7 \mathrm{pM}$.

The results reflect a nearly linear (additive) behavior of DNP and the applied gold nanoparticle-containing suspension. Only a weak synergistic effect can be concluded from the experimental results, shown by the weak non-linear curves for low DNP concentrations.

\section{Microtoxicological screening of the binary mixture of silver nanoparticles and DNP inside microdroplets}

The bacteriostatic effect of silver is well-known. ${ }^{26}$ Despite the broad knowledge of the toxic effect of silver on cells and, in particular, on microorganism, to the best of our knowledge no detailed studies have been reported on the synergistic effects of silver nanoparticles and other toxins.

The critical value for impairing the growth of $E$. coli is much lower in the presence of silver nanoparticles as in the case of gold nanoparticles.

We found EC(50) values of about $90 \pm 3 \mathrm{fmoL} \mathrm{L}^{-1}$ for the investigated $20 \mathrm{~nm}$ silver nanoparticles (Fig. 3b). This value indicates stronger effects of the prepared silver nanoparticles on the viability of $E$. coli cultivated inside microdroplets as described by conventional methods. ${ }^{27}$ The results are still in good agreement with the data reported in literature but strongly dependent on the investigated environmental matrix. ${ }^{28,29}$

Concentrations between 0 and $150 \mathrm{fmoL} \mathrm{L}^{-1}$ silver nanoparticles were investigated for their combinatorial effect with DNP in the concentration range between 0 and $150 \mu \mathrm{moL} \mathrm{L}^{-1}$. For this purpose a micro-fluid segment sequence containing nearly 500 microdroplets was generated. They cover the whole two-dimensional concentration space of both effectors analogous to the experiment with DNP and gold nanoparticles. However, the observed results of the screening including the silver nanoparticles differ significantly from the investigations on gold nanoparticles. A strong synergistic effect was found for the binary mixture of AgNPs and DNP (Fig. 5).
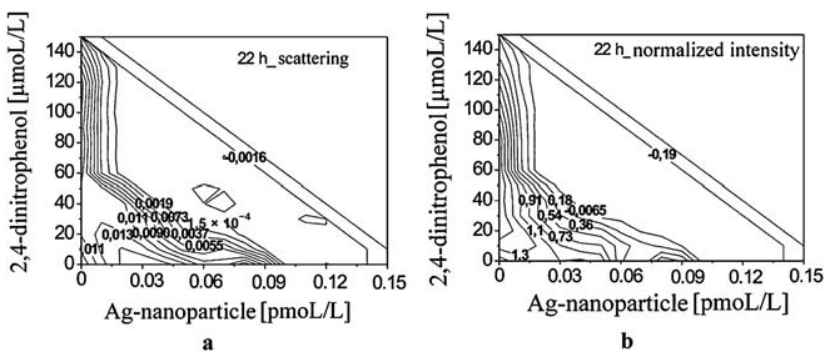

Fig. 5 Isoboles indicating strong interactions between the phenolic uncoupler DNP and silver nanoparticles. (a) Synergistic effects of the binary mixture on the growth of $E$. coli after $24 \mathrm{~h}$ cultivation inside microdroplets. (b) Synergistic effects of the binary mixture on the autofluorescence of $E$. coli after 24 h cultivation inside microdroplets.

The microphotometric measurements of light scattering as well as the microfluorimetric measurements of endogenous cellular autofluorescence show a drastic reduction of the lethal DNP concentrations at comparatively low silver nanoparticle concentrations. A reduction of the lethal dose of DNP from 120 to about $40 \mu \mathrm{moL} \mathrm{L}{ }^{-1}$ was found for a value of only $30 \mathrm{fmoL} \mathrm{L}^{-1}$ silver nanoparticles corresponding to only about $30 \%$ of the lethal dose of silver nanoparticles. At higher silver nanoparticle concentrations $\left(60 \mathrm{fmoL} \mathrm{L} \mathrm{L}^{-1}\right)$ the threshold for the bacterial growth drops down to about $10 \mu \mathrm{moL} \mathrm{L} \mathrm{L}^{-1} \mathrm{DNP}$ corresponding to less than $10 \%$ of the lethal dose of pure DNP. The investigations reflect a massive enforcement of the toxic effect of silver nanoparticles by DNP and, vice versa, a strong enhancement of the toxic effect of DNP by the colloidal suspension of silver nanoparticles.

The combined effects of noble metal nanoparticles and a phenolic uncoupler on the growth and autofluorescence of $E$. coli were studied in microdroplets. The investigation shows the applicability of the microfluidic system for the determination of dose-response functions for toxicological screenings with cells. The technique of microdroplet flow was successfully used for the generation of two-dimensional screening fields by a stepwise variation of binary mixtures.

Only a total volume of $600 \mathrm{~nL}$ of the test solution containing the initial culture of cells, buffer and all effectors was necessary for the realization of two-dimensional screenings. A concentration resolution of about $2 \%$ was obtained with the generation of nearly 500 microdroplets. It could be shown that E. coli cultures responded linearly up to weak interactions to combinations of dinitrophenol and gold nanoparticles. A strong synergistic effect was found for the combination of dinitrophenol with silver nanoparticles.

\section{Conclusion}

The mode of action assessment in microdroplets showed that gold and silver nanoparticles interact differently in the presence of the phenolic uncoupler 2,4-dinitrophenol. The non-toxic tested gold nanoparticle suspension caused additive effects on the growth and the autofluorescence of E. coli in mixtures with DNP. This pointed to a possible interaction of the AgNPs with the phenolic uncoupler. To define the mode of interaction(s), further experiments are required that will extend this study. As to the 
mixture of DNP with the silver nanoparticle suspension a synergistic increase of the antibacterial effects was found. The strong interaction of silver nanoparticles in the presence of a phenolic uncoupler is presumably caused by released silver ions within the cell. The different pathways of endocytosis of metal nanoparticles might also play an important role for the mode of action in the bacteria cells.

Our results demonstrated the high potential of the microdroplet-based technique for the investigation of combinatorial effects in toxicology. Further developments of this powerful method may create an experimental approach to investigate highly resolved two-dimensional dose-response functions for a larger spectrum of toxins and drugs onto different cells and organisms. Eventually, this method will be relevant for future miniaturized screenings in environmental toxicology and drug development as well as related fields to gain detailed information on how cells respond to complex mixtures of substances.

\section{Acknowledgements}

This research was financially supported by the German Federal Environmental Foundation (DBU, 20006/831) and by BMBF (OPTIMI project, 16SV3701). We thank S. Schneider and F. Möller for providing technical support. J. Arning is gratefully acknowledged for discussions of ecotoxicological effects.

\section{References}

1 N. Wangoo, K. K. Bhasin, R. Boro and C. R. Suri, Anal. Chim. Acta, 2008, 610, 142-148.

2 I. Brigger, C. Dubernet and P. Couvreur, Adv. Drug Delivery Rev., 2002, 54, 631-651.

3 S. K. Gogoi, P. Gopinath, A. Paul, A. Ramesh, S. S. Ghosh and A. Chattopadhyay, Langmuir, 2006, 22, 9322-9328.

4 J. Kreuter and S. Gelperina, Tumori, 2008, 94, 271-277.

5 C. Burda, X. B. Chen, R. Narayanan and M. A. El-Sayed, Chem. Rev., 2005, 105, 1025-1102.

6 W. K. Jung, H. C. Koo, K. W. Kim, S. Shin, S. H. Kim and Y. H. Park, Appl. Environ. Microbiol., 2008, 74, 2171-2178.

7 J. H. Niazi and M. B. Gu Toxicity of Metallic Nanoparticles in Microorganisms-A Review, in Atmospheric and Biological Environmental Monitoring, 2009, pp 193-206.
8 A. K. Suresh, D. A. Pelletier, W. Wang, J. W. Moon, B. H. Gu, N. P. Mortensen, D. P. Allison, D. C. Joy, T. J. Phelps and M. J. Doktycz, Environ. Sci. Technol., 2010, 44, 5210-5215.

9 C. L. Brown, M. W. Whitehouse, E. R. T. Tiekink and G. R. Bushell, Inflammopharmacology, 2008, 16, 133-137.

10 C. M. Goodman, C. D. McCusker, T. Yilmaz and V. M. Rotello, Bioconjugate Chem., 2004, 15, 897-900.

11 M. D. Hughes, Y.-J. Xu, P. Jenkins, P. McMorn, P. Landon, D. I. Enache, A. F. Carley, G. A. Attard, G. J. Hutchings, F. King, E. H. Stitt, P. Johnston, K. Griffin and C. J. Kiely, Nature, 2005, 437, 1132-1135.

12 J. Gao, S. Youn, A. Hovsepyan, V. L. Llaneza, Y. Wang, G. Bitton and J. C. Bonzongo, Environ. Sci. Technol., 2009, 43, 3322-3328.

13 I. Shestopalov, J. D. Tice and R. F. Ismagilov, Lab Chip, 2004, 4, $316-$ 321.

14 A. Grodrian, J. Metze, T. Henkel, K. Martin, M. Roth and J. M. Kohler, Biosens. Bioelectron., 2004, 19, 1421-1428.

15 J. M. Kohler and T. Kirner, Sens. Actuators, A, 2005, 119, 19-27.

16 P. M. Gunther, F. Moller, T. Henkel, J. M. Kohler and G. A. Gross, Chem. Eng. Technol., 2005, 28, 520-527.

17 N. Wu, Y. Zhu, S. Brown, J. Oakeshott, T. S. Peat, R. Surjadi, C. Easton, P. W. Leech and B. A. Sexton, Lab Chip, 2009, 9, 33913398.

18 K. Martin, T. Henkel, V. Baier, A. Grodrian, T. Schon, M. Roth, J. M. Kohler and J. Metze, Lab Chip, 2003, 3, 202-207.

19 A. Funfak, A. Brosing, M. Brand and J. M. Kohler, Lab Chip, 2007, 7, 1132-1138.

20 J. Q. Boedicker, L. Li, T. R. Kline and R. F. Ismagilov, Lab Chip, $2008,8,1265-1272$.

21 L. Kvitek, R. Prucek, A. Panacek, R. Novotny, J. Hrbac and R. Zboril, J. Mater. Chem., 2005, 15, 1099-1105.

22 A. M. El Badawy, T. P. Luxton, R. G. Silva, K. G. Scheckel, M. T. Suidan and T. M. Tolaymat, Environ. Sci. Technol., 2010, 44, $1260-1266$.

23 E. Sezgin, O. F. Karatas, D. Cam, I. Sur, I. Sayin, E. Avci, K. Keseroglu, S. Sulek and M. Çulha, Int. J. Nat. Eng. Sci. (Sigma 26), 2008, 26, 227-246.

24 L. M. Browning, K. J. Lee, T. Huang, P. D. Nallathamby, J. E. Lowman and X.-H. N. Xu, Nanoscale, 2009, 1, 138-152.

25 E. T. Hwang, J. H. Lee, Y. J. Chae, Y. S. Kim, B. C. Kim, B. I. Sang and M. B. Gu, Small, 2008, 4, 746-750.

26 P. V. AshaRani, G. L. K. Mun, M. P. Hande and S. Valiyaveettil, ACS Nano, 2009, 3, 279-290.

27 J. S. Kim, E. Kuk, K. N. Yu, J. H. Kim, S. J. Park, H. J. Lee, S. H. Kim, Y. K. Park, Y. H. Park, C. Y. Hwang, Y. K. Kim, Y. S. Lee, D. H. Jeong and M. H. Cho, Nanomedicine, 2007, 3, 95-101.

28 J. P. Ruparelia, A. K. Chatteriee, S. P. Duttagupta and S. Mukherji, Acta Biomater., 2008, 4, 707-716.

29 S. Pal, Y. K. Tak and J. M. Song, Appl. Environ. Microbiol., 2007, 73, $1712-1720$. 